\title{
Musculoskeletal ultrasound as a screening-tool for rheumatoid arthritis: results of the "Rheuma-Truck" screening and awareness initiative
}

\author{
Alexander Lautwein ${ }^{1}$, Benedikt Ostendorf ${ }^{1}$, Stefan Vordenbäumen ${ }^{1}$, Aiko Liedmann ${ }^{1}$, Ralph Brinks', \\ Mario Giulini', Sarah Ohrndorf ${ }^{2}$, Marina Backhaus ${ }^{3}$, Hasan Acar ${ }^{1}$, Oliver Sander ${ }^{1}$, Jutta G. Richter ${ }^{1}$, \\ Matthias Schneider ${ }^{1}$ and Philipp Sewerin ${ }^{1 *}$ (1)
}

\begin{abstract}
Objective: To evaluate musculoskeletal ultrasound (MSUS) as a screening tool for rheumatoid arthritis (RA) and osteoarthritis (OA) patients in a rheumatology-screening program.

Patients and methods: To raise awareness for rheumatic diseases, a mobile rheumatology office was deployed in different cities of Germany ("Rheuma-Truck"). Standardized questionnaire assessment, testing for rheumatoid factor and citrullinated peptide antibodies and medical student driven MSUS of the clinically dominant hand/foot including wrist, MCP-II, -III, -V, PIP-II, -III, MTP-II and -V were offered free of charge to the population. In case of suspicious results, a rheumatologist was consulted.

Results: In MSUS, 192 of 560 selected volunteers (aged 18-89, mean 52.7 years; $72.9 \%$ female) had suspicious findings including synovitis or erosions primarily affecting the MTP-II (11.8\%), dorsal wrist (8.9\%), and MCP-II (7\%). 354 of the 560 volunteers further visited a rheumatologist of whom 76 were diagnosed with RA. According to the 'US7 Score', a sum scores $\geq 5$ was significantly predictive for RA (odds ratio (OR) 5.06; confidence interval (Cl) 0.83-35.32). 313 volunteers displayed signs of OA including osteophytes, while MCP-II (36.2\%), MCP-III (14.8\%), and the wrist (10.5\%) were mostly affected. Diagnosis of RA was favoured over OA if the wrist (OR 4.2; Cl 1.28-13.95), MTP-II (OR 1.62; Cl 1.0-2.6), and MCP-V (OR 2.0; Cl 1.0-3.8) were involved.
\end{abstract}

Conclusion: Medical student driven MSUS by the 'US7 Score' can facilitate diagnosis of RA in rheumatology-screening programs due to the level of the score and the affected joints. A high rate of unknown OA signs was detected by MSUS. A mobile rheumatology office displays an opportunity to screen patients for RA and OA.

Keywords: Musculoskeletal ultrasound, Screening, Rheumatoid arthritis, Osteoarthritis

\section{Key points}

*Correspondence: philipp.sewerin@med.uni-duesseldorf.de

${ }^{1}$ Department and Hiller-Research-Unit for Rheumatology, UKD,

Heinrich-Heine-University Düsseldorf Medical Faculty, Moorenstrasse 5, 40225 Duesseldorf, Germany

Full list of author information is available at the end of the article
In this study musculoskeletal ultrasound (MSUS) was performed as a screening tool for rheumatoid arthritis (RA) and osteoarthritis (OA) in 560 volunteers in a rheumatology-screening program. original author(s) and the source, provide a link to the Creative Commons licence, and indicate if changes were made. The images or other third party material in this article are included in the article's Creative Commons licence, unless indicated otherwise in a credit line to the material. If material is not included in the article's Creative Commons licence and your intended use is not permitted by statutory regulation or exceeds the permitted use, you will need to obtain permission directly from the copyright holder. To view a copy of this licence, visit http://creativecommons.org/licenses/by/4.0/. 
In MSUS, 192 of 560 volunteers had suspicious findings including synovitis or erosions primarily affecting the MTP-II, dorsal wrist, and MCP-II of whom 76 were diagnosed with RA.

MSUS using 'US7 Score' can facilitate diagnosis of RA in rheumatology-screening programs primary driven by the ultrasound score and the number affected joints.

High rate of unknown OA signs was detected by MSUS.

\section{Introduction}

Musculoskeletal ultrasound (MSUS) is a valid imaging tool in rheumatic joint diseases for the detection of soft tissue changes such as synovitis and tenosynovitis, and bony lesions $[1,2]$. Due to the ongoing technical development of high-resolution transducers and bedside imaging formats, MSUS is well accepted by the rheumatology community in both in- and outpatient settings. Moreover, the validated Ultrasound-Score 'US7', which involves seven predefined joints in the MSUS examination, is a time-efficient, standardized alternative to more timeconsuming total joint screens [3]. It was shown that the 'US7 Score' is well suited to document therapy-response in Rheumatoid Arthritis (RA) compared to the Disease Activity Score of 28 joints (DAS28), while the utility for diagnostic purposes is largely unknown [4-6].

Approximately $0.5-1 \%$ of the population suffers from RA $[7,8]$. The final diagnosis after the first symptoms appear is currently delayed by about 1 year [9] (*). Early diagnosis and treatment strategies to target remission are declared aims of both European League Against Rheumatism (EULAR) and American College of Rheumatology (ACR) [10]. However, the clinical diagnosis in early RA may be complicated by unclear clinical findings and unspecific initial symptoms [11]. MSUS is readily available and may facilitate confident early diagnosis [12]. However, the evaluation of subtle changes in early RA made difficult by a lack of large-scale standardized data from the time point of first diagnosis.

Osteoarthritis (OA) is the most common joint disease, which is evident in patients of higher age [13, 14]. Hand OA can cause substantial diagnostic confusion with RA in a primary care setting resulting in increased referral $[15,16]$. Typical signs of OA such as osteophytes can also be recognized by MSUS [17]. Thus, MSUS may facilitate a correct diagnosis in cases that cannot be easily distinguished based on clinical examination. So far, the frequency of typical MSUS changes of the MCP joints such as osteophytes is underestimated. Due to the lack of clinical signs, these are in most cases not recorded in detail until the diagnosis of either OA or RA is made.
Moreover, there is lack of data on the frequency and the pattern of degenerative joints alterations such as osteophytes in patients with joint complaints in general or RA. OA of (several) MCP joints is up to now an underestimated manifestation of hand OA.

In order to overcome these issues, MSUS performed by a well-trained medical student was assessed in a community-based screening and awareness initiative ("RheumaTruck") as a screening tool for RA and OA.

\section{Methods}

\section{Screening initiative and participants}

The "German Cooperative Rheumatology Group RhineRuhr", which is an association of rheumatology caregivers including university-hospitals, university teaching hospitals, and rheumatologists in outpatient practices within a metropolitan area of approximately 10 million inhabitants in western Germany, initiated the "RheumaTruck"-initiative. This initiative was supported by financial contribution of Roche Pharma AG Germany and Chugai Pharma Marketing Ltd. in form of an unconditional grant. Consisting of a mobile rheumatology office, "Rheuma-Truck" offered a screening for rheumatic diseases temporarily located at 22 different city centers of the federal state of North Rhine-Westphalia including Düsseldorf, Wuppertal, Hagen, Ratingen, Essen, Herne, Gelsenkirchen, Gladbeck, Duisburg, Bochum, Bottrop, Köln, Krefeld, Mettmann, Neuss, Kamp-Lintford, Velbert, Wesel, Emmerich, Kleve and Mönchengladbach, some of them twice over a total duration of 26 days. In total, 7333 people participated by volunteering in the program. The screening included (1) the validated "Rheuma-Check" questionnaires [18]. The "RheumaCheck" questionnaire was developed on the basis of the FDA-approved validated CSQ questionnaire. After translation and back-translation of the CSQ questionnaire by two independent interpreters a final German version of the questionnaire was created, which was given the name "RheumaCheck". The Rheuma-Check consists of 30 questions, which have to be answered with "yes" or "no". The RheumaCheck questions record the spectrum of symptoms of the following inflammatory rheumatic diseases diseases: systemic lupus erythematosus (SLE), rheumatoid arthritis (RA), systemicarthritis (RA), systemic scleroderma (PSS), dermato- and polymyositis (DM/PM), Sjögren's syndrome, Raynaud's syndrome and syndrome, and mixed connective tissue disease (MCTD). RheumatismCheck algorithm showed a high sensitivity (77.6\%) and specificity $(79.9 \%)$ at a cutpoint of $>3$. (79.9\%) [18]. (2) A bed-side laboratory testing for Mutated Citrullinated Vimentin (MCV) antibodies and Rheumatoid Factor (RF) (ORGENTEC Diagnostika GmbH, Germany). If the questionnaire assessment or the laboratory markers 
either individually or collectively yielded a pathological result, (3) MSUS was conducted and (4) the participant was then directly referred to a board-certified rheumatologist for an initial consultation and if necessary, for further follow-up visits in an outpatient rheumatology clinic. RA was defined by fulfilling the ACR/EULAR classification criteria 1987 [19]. The study was conducted in agreement with the principles of the Declaration of Helsinki, the International Conference on Harmonization Guidance for Good Clinical Practice and approved by local ethic committee of Heinrich-Heine-University Düsseldorf (3249). All patients provided written informed consent.

\section{Musculoskeletal ultrasound}

MSUS was performed in 560 participants [72.9\% female $(\mathrm{n}=408)$; age $18-89$ years (mean 52.72 years; median 55 years, \pm 9.01$)$ ] if (1) "Rheuma-Check" or (2) bedside laboratory testing (MVC or RF) showed a pathological result.

The MSUS was conducted by a qualified medical student after specialized training with rheumatologist and ultrasound experts ( $\mathrm{OS}$ and $\mathrm{BO}$ ). The students were recruited from different semesters (min. at least 4 years of academic study) and received $25 \mathrm{~h}$ of training in the use of ultrasound and in the differentiation of inflammatory and osteoarthritic alterations from two experts with an experience of nearly 20 years (BO and OS) according to the structured training program of the German Society for Rheumatology and the German Society of Ultrasound medicine. All investigations were conducted on a MyLab 25 Gold (Esaote linear scanner, 15, Type LA435) using B-mode ultrasound for synovitis and erosions. A PowerDoppler was not used during the MSUS investigations. MSUS was performed according to the 'US7 Score' [5] including seven joints of the clinically dominant hand (wrist, MCP-II and III, PIP-II and III) and foot (MTP-II and MTP-V). Additionally, we investigated the MCP-V joint, which has proven to be an important target joint, especially for the detection of (early) erosions in RA [20]. According to the 'US7' synovitis was scored on a scale from 0 defined as no signs for synovitis to 3 defined as severe signs for synovitis according to Szkudlarek, Terslev [20]. Erosions were scored as 0 for being absent and 1 for being present. Offering MSUS of the dominant hand and foot to all participants, all 560 of these volunteers participated in the MSUS of the hand, while 221 investigations of the feet were performed. Thus, a total of 3497 joints were examined by MSUS. Additionally to inflammatory signs, MSUS-signs of osteoarthritis, defined as the presence of osteophyte formations were assessed in every MSUS investigated participant (discrete, moderate or severe) (see Fig. 1). The student scored the dynamic images immediately during the investigation according to the 'US7 Score' examination $[5,6]$ and stored representative standing images. The specialist $\mathrm{BO}, \mathrm{OS}, \mathrm{SO}, \mathrm{MB}$ and PS scored the standing images later, to assess the interrater reliability.
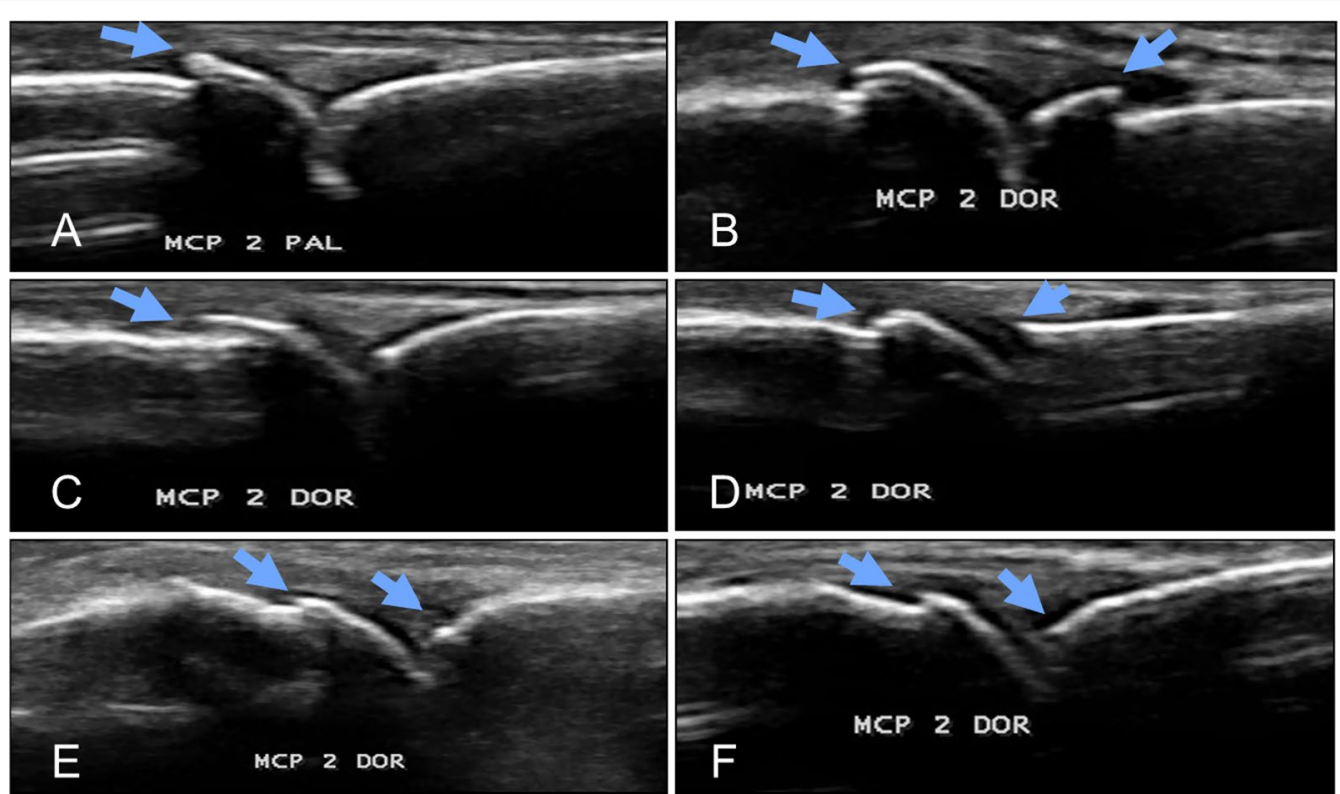

Fig. 1 Grading of osteophytes. Grading of OA signs in the longitudinal section plane: Grade III (severe) was defined as at least two osteophytes (a b); Grade II (moderate) was defined as the availability of isolated small osteophytes (c, d); Grade I (discrete) was as uneven joint surface (e, $\mathbf{f})$ 


\section{Interrater-reliability}

Dynamic images were analyzed during the MSUS according to the'US7 Score' by a trained medical student. Standing images were stored in a standardized manner in palmar and dorsal section planes. These images were assessed by specialists (OS, BO, PS, SO or MB) blinded to the dynamic scoring. The agreement between all raters as well as between raters of dynamic images and raters of standing images were calculated. Results are displayed as both the percentage of study subjects (1) with identical score ratings and (2) with a tolerance of \pm one-point deviation in score ratings.

\section{Statistical analyses}

Descriptive statistics for the patients were obtained and are reported as means \pm standard deviation, ranges, frequencies or proportions as appropriate. Correlation coefficients were calculated according to Pearson with SAS, version 9.3 (SAS Institute, Cary, North Carolina). The respective odds ratio and confidence intervals are given for the relationship between 'US7' and the diagnosis RA, as well as for joint involvement and the diagnosis of RA and OA.

\section{Results}

\section{Inflammatory signs}

Inflammatory signs in MSUS defined as a B-mode synovitis-score $\geq 1$, were observed in 192 of the 560 selected participants [31.5\%; 143 females (74\%)] representing $2.6 \%$ of all unselected participants. Overall, MTP-II was the most frequently involved joint (26 of $221 ; 11.8 \%$ ) followed by the wrist as shown in Fig. 2. The additionally investigated MCP-V, which is not part of the 'US7 Score', was affected in $7.5 \%$ of the selected participants. Most

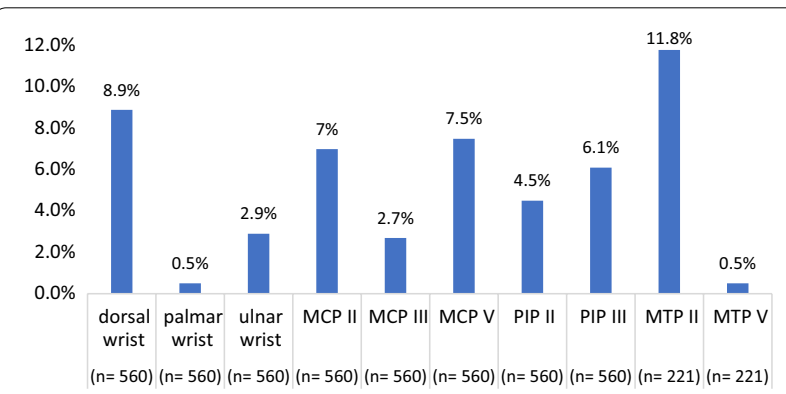

Fig. 2 Synovitis in MSUS. Inflammatory signs of the investigated joints with a synovitis score $\geq 1$ according to 'US7'. This includes the dorsal, palmar and ulnar wirst, the metacarpophalangeal joints 2, 3 and 5 (MCP-II, MCP-III and MCP-V), as well als the proximal interphalangeal joints 2 and 3 (PIP-II and PIP-III) with were investigated in 560 participants. Additionally, the metatarsophalangeal joints 2 and 5 (MTP-II and MTP-V) were investigated in 221 participants participants with inflammatory signs showed a synovitis score of grade 1 (110 of 192; 57\%) with higher categories in descending order as depicted in Fig. 3.

\section{Rheumatoid arthritis (RA)}

Due to positive 'Rheuma-Check' and/or bedside laboratory testing, 354 of 560 participants were preselected and took their opportunity to visit a rheumatologist. RA was diagnosed in 76 of these 354 volunteers (59 females (78\%) and 17 males (22\%)). Regarding these RA patients, 28/76 (36.8\%) showed a positive MSUS-Score $(\geq 1)$ according to the 'US7' sum score for synovitis using B-Mode. The non-RA patients, 104/278 (37.4\%) showed a positive MSUS-Score $(\geq 1)$ (Table 1). On average, RA-patients had higher MSUS-Scores. MSUS-Scores $\geq 5$ was a possible predictor for the diagnosis of RA (odds ratio (OR) 5.06; confidence interval (CI) 0.83-35.32). Additionally, $15.8 \%$ of the MSUS-positive participants had only pathological findings in the feet.

\section{Osteoarthritis (OA)}

Sonographically detectable signs for OA were observed in 313 of $560(55.9 \%)$ selected participants $(4.3 \%$ of all participants) in the investigated joints. Of these

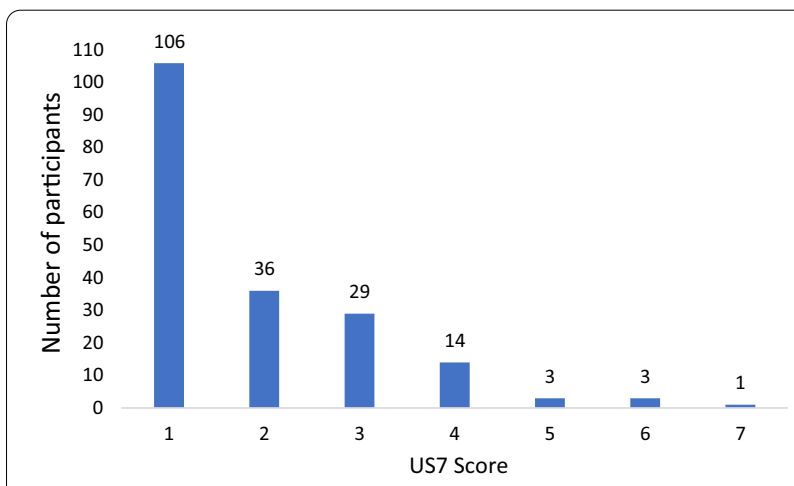

Fig. 3 Grading according to 'US7 Score'. Grading for inflammatory signs according to the 'US7'. 192 out of 560 participants showed a score of $\geq 1$ in the investigated joints. These include the dorsal, palmar and ulnar wirst, the metacarpophalangeal joints 2, 3 and 5 (MCP-II, MCP-III and MCP-V), as well als the proximal. interphalangeal joints 2 and 3 (PIP-II and III) with were investigated in 560 participants. Additionally, the metatarsophalangeal joints 2 and 5 (MTP-II and V) were investigated in 221 participants

Table 1 MSUS scoring and RA diagnosis

\begin{tabular}{lll}
\hline Diagnosis of RA & Negative & Positive \\
\hline MSUS: score $\geq 1$ & 174 & 48 \\
MSUS: negative & 104 & 28 \\
\hline
\end{tabular}

MSUS results and RA diagnosis of 354 out of 560 participants, which underwent the MSUS investigation and visited a rheumatologist for further assessment 
volunteers with sonographically positive OA signs, 73.5\% were older than 50 years, $13.1 \%$ between 40 and 50 years, $4.8 \%$ between 30 and 40 years and $8.6 \%$ under 30 years. MCP-II was the most frequently involved joint, wherein $36.2 \%$ of the sonographically positive OA volunteers showed osteophytes followed by the other assessed joints as shown in Fig. 4.

\section{OA and RA}

Signs of both OA and RA were found in 8.2\% (46 of 560) of all participants evaluated with the MSUS. Of the patients diagnosed with RA, $60.5 \%$ (46 of 76) also showed sonographically detectable OA-signs. When analyzing patients who were diagnosed with RA and showed MSUS signs of OA, the diagnosis of RA was significantly associated with involvement (B-Mode synovitis score) of the

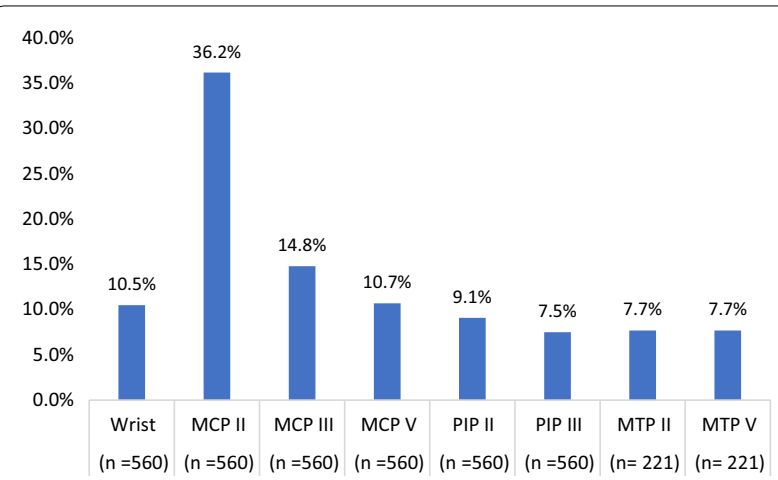

Fig. 4 Osteophytes in MSUS. Percentage of sonographically detectable OA signs of the investigated joints. These include the dorsal, palmar and ulnar wirst, the metacarpophalangeal joints 2, 3 and 5 (MCP-II, MCP-III and V), as well als the proximal interphalangeal joints 2 and 3 (PIP-II and III) with were investigated in 560 participants. Additionally, the metatarsophalangeal joints 2 and 5 (MTP-\|l and V) were investigated in 221 participants wrist (OR 4.2; CI 1.28-13.95), MTP-II (OR 1.62; CI 1.02.6) and MCP-V (OR 2.0; CI 1.0-3.8).

\section{Interrater-agreement ultrasound}

The absolute agreement of score ratings for all investigators (PS, BO, OS, SO or MB on standing images, medical student on dynamic images) were between 62\% (dorsal wrist) and 98\% (palmar wrist). If one point of difference was permitted, the agreement was between $87 \%$ (dorsal wrist) and 100\% (palmar wrist) (Table 2).

The agreement between standing images (post hoc analyzed by PS, BO, OS, SO or MB) and dynamic assessment (scored by medical student) was between $48 \%$ (dorsal wrist) and 100\% (ulnar wrist and MTP 5) and between 97\% (PIP 2) and 100\% (all other joints) if one point of difference was permitted (Table 2).

\section{Discussion}

RA is the most common inflammatory joint disease [21]. Early diagnosis and treat-to-target interventions are of high importance in the prevention of irreversible cartilage and bony lesions in RA patients [10]. However, the diagnostic process still takes approximately one year, even in countries with a well-developed health care system such as Germany [22]. While MSUS (under application of composite scores such as the 'US7 Score') is a sensitive therapy-monitoring tool that correlates well with DAS28 and magnetic resonance imaging (MRI) [4, 23 ], its value as a screening tool performed by the trained student in cohorts with undiagnosed rheumatic diseases is not sufficiently studied so far. Thus, cross sectional prospective MSUS data of the "Rheuma Truck" initiative were assessed.

A high number of healthy volunteers showed inflammatory signs in MSUS, albeit most of them with low score values and mostly one affected joint only. Recently,

Table 2 Interrater-agreement

\begin{tabular}{|c|c|c|c|c|}
\hline \multirow{2}{*}{$\begin{array}{l}\text { Agreement between } \\
\text { Tolerance }\end{array}$} & \multicolumn{2}{|c|}{ All investigators } & \multicolumn{2}{|c|}{ Standing and dynamic imaging } \\
\hline & \pm 0 points $(\%)$ & \pm 1 point (\%) & \pm 0 points $(\%)$ & \pm 1 point $(\%)$ \\
\hline Dorsal wrist & 62 & 87 & 48 & 100 \\
\hline Palmar wrist & 98 & 100 & 97 & 100 \\
\hline Ulnar wrist & 87 & 94 & 100 & 100 \\
\hline MCP 2 & 77 & 94 & 66 & 100 \\
\hline MCP 3 & 85 & 94 & 93 & 100 \\
\hline PIP 2 & 70 & 91 & 79 & 97 \\
\hline PIP 3 & 81 & 91 & 90 & 100 \\
\hline MTP 2 & 72 & 89 & 90 & 100 \\
\hline MTP 5 & 96 & 98 & 100 & 100 \\
\hline
\end{tabular}

Agreement between all investigates for inflammatory signs according to the 'US7 Score' as well as between standing images (post hoc evaluation by specialists) and dynamic assessment (by the trained medical student). Results are presented with a permitted deviation of one point and without permitting a deviation 
Jindal et al. confirmed the high sensitivity of ultrasound in the detection of inflammation in RA patients [24]. However, it was shown in numerous studies that pathological findings such as signs of synovitis or erosions could be detected by MSUS in healthy volunteers [2527]. This similarly applies to MRI [25]. In contrast, high MSUS-scores for arthritis/inflammation $(\geq 5)$ were predictive for the initial diagnosis of RA in our cohort.

Another important result of our study relates to the value of MSUS of the feet. 15.8\% of the volunteers showed pathological MSUS findings of the feet exclusively. Even though the feet were investigated in only 221 volunteers $(39.4 \%)$, MTP-II seems to be the most frequently involved joint. This is in line with our previous reports demonstrating a high number of sustained inflammatory signs in MRI of RA patients' feet [28]. Consequently, these data underline the value of the additional investigation of the feet in patients with inflammatory joint diseases, which is not part of the DAS28 and besides the conventional $x$-ray investigation often neglected in daily practice.

In the "Rheuma Truck" cohort, more than half of the selected participants (55.6\%) showed OA-compatible sonographic findings, while almost 3 out of 4 of them were over 50 years old. Furthermore, nearly $14 \%$ of newly diagnosed OA according to sonographic findings were below the age of 40. MCP-II (36.2\%) and MCP-III (14.8\%) were the most frequently involved of the investigated joints, which however ignores the PIP I, IV and V as well as the DIP-joints. In daily clinical practice, the affection of MCP joints is often not perceived and especially the $\mathrm{OA}$ in MCP II is commonly interpreted as a possible hemochromatosis arthropathy. However, the progression of OA in the MCP to a later clinical meaningful or in $\mathrm{X}$-ray detectable manifestation is rarely seen $[14,29]$. In addition, our study highlights a previously unrecognized high burden of hand OA in RA-patients with $60.5 \%$ of all newly diagnosed RA patients showing also sonographic OA signs. This is of high importance, as bony changes and soft tissue thickening can be clinically misinterpreted as joint swelling due to RA and may thus lead to overdiagnosis and overtreatment. Vice versa, RA patients with clinical signs for OA could be misinterpreted as "purely OA". According to the present data, MSUS may help to distinguish between "purely" OA and additional presence of RA: inflammatory MSUS findings in the wrist, MTP-II and MCP-V greatly favor an additional diagnosis of RA.

Most commonly, MSUS is used and evaluated dynamically [6], which means that physicians analyze and document the results immediately after the investigation. This procedure requires trained physicians, which is a clear obstacle to larger studies due to cost restrictions. In the current study, we delegated MSUS to a trained medical student. We could show good intra- and interrater agreements when the student is systematically trained by specialists [30]. Moreover, the agreement between standing images and dynamic interpretation by using the 'US7' synovitis score was excellent with consensus of $99.7 \%$ if one point of difference was permitted. This opens new perspectives for future larger scale prospective MSUS studies.

This study has limitations. MSUS of the feet was performed in only 221 participants, which were selected according to rather weak criteria such as reported pain of the feet and willingness to undress the feet. Furthermore, the MSUS were performed only for synovitis and erosions excluding tenosynovitis and without using Power-Doppler-Ultrasound, which may render additional information [31]. Moreover, the included participants were not recruited using a structured procedure. Rather, volunteers were invited to be assessed in a structured setting. However, these individuals would probably also be more likely to seek rheumatological advice in a standard health care setting and therefore represent a relevant patient group.

\section{Conclusion}

MSUS facilitates the diagnosis of RA. While low US7 sum scores were frequent found in healthy persons, scores $\geq 5$ were highly predictive for the initial diagnosis of RA. More than $55 \%$ of the volunteers showed sonographic signs for hand OA, wherein MCP-II joint was the most frequently involved. In patients with signs of both OA and RA, inflammation in the wrist, MTP-II and MCP-V was significantly predictive for the diagnosis of RA. Due to the good Interrater-agreement, the delegation of MSUS to trained medical students or medical health care professionals is a viable option for future studies and daily practice.

\section{Abbreviations \\ ACR: American College of Rheumatology; DAS28: Disease activity score of 28 joints; EULAR: European league against rheumatism; MCP: Metacarpophalan- geal; MSUS: Musculoskeletal ultrasound; MTP: Metatarsophalangeal; OA: Osteoarthritis; PIP: Proximal interphalangeal; RA: Rheumatoid arthritis.}

\section{Acknowledgements}

We thank the Rheumazentrum Rhein-Ruhr e.V for the continuous support during that study, especially Ms. Martina Brandes.

\section{Authors' contributions}

$\mathrm{AL}$ : Interpretation and analysis of data. Draft and design of the work. Revision of the work. BO: Design and conception of the study. Interpretation and analysis of data. Draft and design of the work. Revision of the work. SV: Design and conception of the study. Interpretation and analysis of data. Draft and design of the work. Revision of the work. ALm: Acquisition, and conception of the study. Draft and design of the work. Revision of the work. RB: Analysis and interpretation of data. Draft and design of the work. Revision of the work. MG: Interpretation and analysis of data. Draft and design of the work. Revision of the work SO: Interpretation and analysis of data. Draft and design of the work. 
Revision of the work MB: Interpretation and analysis of data. Draft and design of the work. Revision of the work HA: Design and conception of the study. Draft and design of the work. Revision of the work. OS: Design and conception of the study. Analysis and interpretation of data. Draft and design of the work. Revision of the work. JGR: Design and conception of the study. Analysis and interpretation of data. Draft and design of the work. Revision of the work. MS: Design and conception of the study. Analysis and interpretation of data. Draft and design of the work. Revision of the work. PS: Design and conception of the study. Analysis and interpretation of data. Draft and design of the work. Revision of the work. All authors have read and approved the manuscript.

\section{Funding}

This research received no external funding.

\section{Availability of data and materials}

The data that support the findings of this study are available on request from the corresponding author.

\section{Declarations}

\section{Ethics approval and consent to participate}

The study was conducted in agreement with the principles of the Declaration of Helsinki, the International Conference on Harmonization Guidance for Good Clinical Practice and approved by local ethic committee of Heinrich-HeineUniversity Düsseldorf (3249). All patients provided written informed consent.

\section{Consent for publication}

Not applicable.

\section{Competing interests}

The authors declare that they have no competing interests.

\section{Author details}

${ }^{1}$ Department and Hiller-Research-Unit for Rheumatology, UKD, HeinrichHeine-University Düsseldorf Medical Faculty, Moorenstrasse 5, 40225 Duesseldorf, Germany. ${ }^{2}$ Department of Rheumatology and Clinical Immunology, Charité-Universitätsmedizin Berlin, Berlin, Germany. ${ }^{3}$ Department of Internal Medicine, Rheumatology and Clinical Immunology, Academic Hospital of the Charité Berlin, Park-Klinik Weissensee Berlin, Berlin, Germany.

Received: 7 July 2021 Accepted: 20 December 2021

Published online: 04 January 2022

\section{References}

1. Alcalde M, D'agostino MA, Bruyn GA, Möller I, lagnocco A, Wakefield RJ, et al. A systematic literature review of US definitions, scoring systems and validity according to the OMERACT filter for tendon lesion in RA and other inflammatory joint diseases. Rheumatology. 2012;51(7):1246-60.

2. Mandl P, Naredo E, Wakefield RJ, Conaghan PG, D'Agostino MA. A systematic literature review analysis of ultrasound joint count and scoring systems to assess synovitis in rheumatoid arthritis according to the OMERACT filter. J Rheumatol. 2011;38(9):2055-62.

3. Zufferey P, Tamborrini G, Gabay C, Krebs A, Kyburz D, Michel B, et al. Recommendations for the use of ultrasound in rheumatoid arthritis: literature review and SONAR score experience. Swiss Med Wkly. 2013;143:w13861.

4. Backhaus TM, Ohrndorf S, Kellner H, Strunk J, Hartung W, Sattler H, et al. The US7 score is sensitive to change in a large cohort of patients with rheumatoid arthritis over 12 months of therapy. Ann Rheum Dis. 2013;72(7):1163-9.

5. Backhaus M, Ohrndorf S, Kellner H, Strunk J, Backhaus T, Hartung W, et al. Evaluation of a novel 7-joint ultrasound score in daily rheumatologic practice: a pilot project. Arthritis Care Res Off J Am Coll Rheumatol. 2009;61(9):1194-201.

6. Ohrndorf S, Fischer I, Kellner H, Strunk J, Hartung W, Reiche B, et al. Reliability of the novel 7-joint ultrasound score: Results from an inter-and intraobserver study performed by rheumatologists. Arthritis Care Res. 2012;64(8):1238-43.

7. Symmons DP. Epidemiology of rheumatoid arthritis: determinants of onset, persistence and outcome. Best Pract Res Clin Rheumatol. 2002;16(5):707-22.

8. Zeidler H, Merkesdal S, Hulsemann J. Early arthritis and rheumatoid arthritis in Germany. Clin Exp Rheumatol. 2003;21(5):S106-12.

9. Zink A, Schmidt R, Edelmann E. Versorgungsforschung in der rheumatologie. Z Rheumatol. 2019;78(8):701-2.

10. Smolen JS, Landewé R, Bijlsma J, Burmester G, Chatzidionysiou K, Dougados $M$, et al. EULAR recommendations for the management of rheumatoid arthritis with synthetic and biological disease-modifying antirheumatic drugs: 2016 update. Ann Rheum Dis. 2017;76(6):960-77.

11. Lampropoulos C, Orfanos P, Manoussakis M, Tzioufas A, Moutsopoulos $H$, Vlachoyiannopoulos P. Treat-to-target biologic therapy in patients with rheumatoid arthritis is more efficacious and safe compared to delayed initiation of biologics: a real-world study. Clin Exp Rheumatol. 2017;35(2):192-200.

12. Wang MY, Wang XB, Sun XH, Liu FL, Huang SC. Diagnostic value of high-frequency ultrasound and magnetic resonance imaging in early rheumatoid arthritis. Exp Ther Med. 2016;12(5):3035-40.

13. Tsezou A. Osteoarthritis year in review 2014: genetics and genomics. Osteoarthr Cartil. 2014;22(12):2017-24

14. Martel-Pelletier J, Barr AJ, Cicuttini FM, Conaghan PG, Cooper C, Goldring MB, et al. Osteoarthritis. Nat Rev Dis Primers. 2016:2:16072.

15. Andersson SF, Bergman S, Henriksson EW, Bremander A. Arthritis management in primary care-a study of physiotherapists' current practice, educational needs and adherence to national guidelines. Musculoskelet Care. 2017;15(4):333-40.

16. MCWilliams DF, Marshall M, Jayakumar K, Doherty S, Doherty M, Zhang W, et al. Erosive and osteoarthritic structural progression in early rheumatoid arthritis. Rheumatology. 2016;55(8):1477-88.

17. Hammer HB, lagnocco A, Mathiessen A, Filippucci E, Gandjbakhch F, Kortekaas MC, et al. Global ultrasound assessment of structural lesions in osteoarthritis: a reliability study by the OMERACT ultrasonography group on scoring cartilage and osteophytes in finger joints. Ann Rheum Dis. 2016;75(2):402-7.

18. Richter JG, Wessel E, Klimt R, Willers R, Schneider M. RheumaCheck: development and evaluation of a German language screening instrument for rheumatic diseases. Wien Klinische Wochenschr. 2008;120(3-4):103-11.

19. Arnett FC, Edworthy SM, Bloch DA, Mcshane DJ, Fries JF, Cooper NS, et al. The American Rheumatism Association 1987 revised criteria for the classification of rheumatoid arthritis. Arthritis Rheum Off J Am Coll Rheumatol. 1988:31(3):315-24

20. Szkudlarek M, Terslev L, Wakefield RJ, Backhaus M, Balint PV, Bruyn GA et al. Summary findings of a systematic literature review of the ultrasound assessment of bone erosions in rheumatoid arthritis. J Rheumatol. 2016;43(1):12-21.

21. Smolen JS, Aletaha D, McInnes IB. Rheumatoid arthritis. Lancet. 2016;388(10055):2023-38

22. Zink A. Versorgungsforschung in der Rheumatologie. Z Rheumatol. 2014;73(2):115-22.

23. Schmidt W, Schicke B, Ostendorf B, Scherer A, Krause A, Walther M. Lowfield MRI versus ultrasound: which is more sensitive in detecting inflammation and bone damage in MCP and MTP joints in mild or moderate rheumatoid arthritis. Clin Exp Rheumatol. 2013;31(1):91-6.

24. Jindal S, Kaushik R, Raghuvanshi S, Kaushik RM, Kakkar R. Gray scale and power Doppler ultrasonographic findings in the assessment of disease activity and their correlation with disease activity parameters in rheumatoid arthritis. Curr Rheumatol Rev. 2018;14(2):153-62.

25. Mangnus L, Van Steenbergen H, Reijnierse M, van der Helm-van Mil A Magnetic resonance imaging-detected features of inflammation and erosions in symptom-free persons from the general population. Arthritis Rheumatol. 2016;68(11):2593-602

26. Fodor D, Felea I, Popescu D, Moței A, Ene P, Şerban O, et al. Ultrasonography of the metacarpophalangeal joints in healthy subjects using an 18 MHz transducer. Med Ultrasonogr. 2015;17(2):185-91.

27. Padovano I, Costantino F, Breban M, D'agostino MA. Prevalence of ultrasound synovial inflammatory findings in healthy subjects. Ann Rheum Dis. 2016;75(10):1819-23. 
28. Sewerin P, Buchbender C, Vordenbäumen S, Scherer A, Miese F, Brinks $R$, et al. Advantages of a combined rheumatoid arthritis magnetic resonance imaging score (RAMRIS) for hand and feet: Does the RAMRIS of the hand alone underestimate disease activity and progression? BMC Musculoskelet Disord. 2014;15(1):104.

29. Leung GJ, Rainsford KD, Kean WF. Osteoarthritis of the hand I: aetiology and pathogenesis, risk factors, investigation and diagnosis. J Pharm Pharmacol. 2014;66(3):339-46.

30. Hammer HB, Bolton-King P, Bakkeheim V, Berg TH, Sundt E, Kongtorp AK et al. Examination of intra and interrater reliability with a new ultrasonographic reference atlas for scoring of synovitis in patients with rheumatoid arthritis. Ann Rheum Dis. 2011;70(11):1995-8.

31. Terslev L, lagnocco A, Bruyn GAW, Naredo E, Vojinovic J, Collado P, et al. The OMERACT ultrasound group: a report from the OMERACT 2016 meeting and perspectives. J Rheumatol. 2017;44(11):1740-3.

\section{Publisher's Note}

Springer Nature remains neutral with regard to jurisdictional claims in published maps and institutional affiliations.

- fast, convenient online submission

- thorough peer review by experienced researchers in your field

- rapid publication on acceptance

- support for research data, including large and complex data types

- gold Open Access which fosters wider collaboration and increased citations

- maximum visibility for your research: over $100 \mathrm{M}$ website views per year

At BMC, research is always in progress.

Learn more biomedcentral.com/submissions 